\title{
From COVID to Cancer, is Vitamin C the Answer?
}

\author{
Anita Vazquez Tibau ${ }^{1 *}$ and Blanche D Grube ${ }^{2}$ \\ ${ }^{1}$ Center for Environmental and Toxicological Research, University of Puerto Rico, Puerto Rico \\ ${ }^{2}$ Past President of the International Academy of Biological Dentistry \& Medicine (IABDM), Pennsylvania
}

Submission: May 01, 2020; Published: May 07, 2020

*Corresponding author: Anita Vazquez Tibau, Center for Environmental and Toxicological Research, University of Puerto Rico, Puerto Rico

Keywords: COVID-19; Cancer stem cells; Vitamin C; Supplements; Linus pauling; Ascorbic acid

\section{Short Communication}

The controversy between pharmaceutical drugs and supplements is ever present in global society, especially now, in the media during the current Covid-19 virus. One of the most important, yet, provocative supplements is vitamin C. While historically, its positive benefits have long been known, during the last decades the push for pharmaceutical drugs, instead of supplements like vitamin $\mathrm{C}$, has created a heated debate against this, and other very affordable supplements. The majority of primates, including humans, guinea pigs, some birds and fish do not make vitamin $\mathrm{C}$, however, most mammals are able to synthesize it in their liver or kidneys. The result of this genetic mutation in humans, therefore, requires vitamin $\mathrm{C}$ to be consumed through dietary sources. Clinical studies indicate that vitamin $C$ neither increases nor reduces the occurrence of kidney stones, it also has no mutagenic effect with up to $5000 \mathrm{mg}$ per day [1].

During the era that was known as the Age of Sail, vitamin C deficiency was recognized and referred to as "scurvy", a disease that was an extremely common affliction amongst sailors. The major signs of scurvy included swollen and bleeding gums, tooth loss, and delays in wound healing. Scurvy was the leading cause of death to sailors during the 16th to 18th centuries [2]. Even though scurvy was referenced in the late 1400's, it has taken hundreds of years to fully understand the importance of vitamin $\mathrm{C}$, and its necessary and positive impact on human health. In more recent times there have been notable figures who advanced the scientific knowledge of vitamin C. One such person was Albert SzentGyorgyi, a Nobel Prize winner for his work in Physiology and Medicine, who isolated vitamin C in 1928, which subsequently led to the treatment and prevention of scurvy [3].
Like Nobel Prize winner Szent-Gyorgyi, decades later, two-time Nobel Prize winner, Dr. Linus Pauling, an American theoretical physical chemist, was the only person to have ever won two unshared Nobel Prizes. His first prize (1954) was awarded for research into the nature of the chemical bond and its use in elucidating molecular structure; the second (1962) recognized his efforts to ban the testing of nuclear weapons. His contributions to science and humanity earned him the title of one of the 20 greatest scientists of all time, by New Scientist, and the 16th most important scientist in history. Later in his career, Pauling became interested in "Orthomolecular" medicine, a term he coined, and defined as medicine that treats and prevents diseases, by utilizing optimal amounts of substances natural to the body. He developed a keen interest in vitamin $\mathrm{C}$, researched and published the best seller, "Vitamin C and the Common Cold (1970)", which introduced taking mega doses of vitamin $\mathrm{C}$ to help fight the common cold and other diseases [4].

A scientific paper titled, "Supplemental ascorbate in the supportive treatment of cancer: Prolongation of survival times in terminal human cancer* (vitamin C)" by Cameron and Pauling (1976), found that cancer patients were considerably deficient in ascorbic acid. Their clinical study presented 100 terminally ill cancer patients who were given ascorbate as part of their treatment protocol. The controls consisted of 1000 similarly treated patients, who did not receive ascorbate in their protocol. The patients who were on ascorbate survived more than 4.2 times longer, than the controls. They noted that this simple and safe treatment, was of great value to terminally ill cancer patients [5]. 


\section{Global Journal of Otolaryngology}

Intravenous (IV) vitamin C has been used in various therapeutic protocols to treat cancer since the 1970's. Like Pauling had discovered, those whose cancers were most destructive, were also most deficient in vitamin C. Current clinical trials are showing that vitamin $\mathrm{C}$ reduces the negative effects of chemotherapy. When mega doses of vitamin $\mathrm{C}$, in addition to anticancer therapies are used, tumor growth is inhibited in models of pancreatic, liver, prostate, ovarian cancer, sarcoma and malignant mesothelioma. It was observed that vitamin $\mathrm{C}$ provides valuable positive effects through more than one mechanism, some are linked to the metabolism of transformed cells, and others may involve direct interactions with specific drugs [6].

Harris et al. investigated the survival among women with breast cancer, the most commonly diagnosed cancer of women globally. They found that various supplementation is widespread amongst breast cancer survivors, with vitamin $\mathrm{C}$ being the most frequently consumed. In their meta-analysis, they observed that the consumption of vitamin $\mathrm{C}$ had a statistically significant correlation with a decreased risk of total death, and breast cancerspecific death [7]. A study by Lv et al. [8] examined the effects of vitamin $\mathrm{C}$ on hepatocellular carcinoma (HCC) and liver cancer cells in 613HCC patients, who had liver resection as their first treatment. In vitro and in vivo experiments revealed that clinically achievable concentrations of vitamin C provoked cell death in liver cancer cells and preferentially destroyed liver cancer stem cells.

Therefore, this evidenced based study supports vitamin C as a novel therapy for HCC treatment [8]. The side effects caused by conventional treatments for cancers such as surgery, chemotherapy, and radiation can in themselves be devastating to the patient. More recently, research is focusing on cancer stem cells and how they impact the beginning of tumors, progression, metastasis, drug resistance, and recurring disease. Traditional cancer treatments are shown to fail when cancer stem cells are not targeted, but also show the toxic effects to normal cells caused by those treatments. Ascorbic acid/vitamin C is a powerful antioxidant, and is a cofactor for several biosynthetic and gene regulatory enzymes and is critical for a healthy immune system. Studies are showing that using a combination therapy that includes vitamin $\mathrm{C}$, should be utilized in cancer treatment plans [9].

Using vitamin $\mathrm{C}$ to treat viruses is also not a novel idea, in fact a scientific paper published in 1935 , found that extremely small amounts of vitamin $\mathrm{C}$ had the ability to inactivate diphtheria toxins in vitro and in vivo. Because of these revolutionary findings, a study was conducted to see what the results would be on the poliomyelitis virus. The study used 30 rhesus monkeys and 5 controls by injecting them with the Aycock passage virus strain, $0.1 \mathrm{cc}$. Of the supernatant of a centrifuged $10 \%$ poliomyelitis cord suspension and vitamin C. The controls received the same amount of virus mixed with saline or distilled water.

The doses of vitamin $\mathrm{C}$ varied from as much as $100 \mathrm{mg}$. to as little as $0.05 \mathrm{mg}$. The quantities were obtained by progressive dilutions with distilled water of a freshly prepared $5 \%$ solution of vitamin $\mathrm{C}$, the respective doses always contained in a volume of $1 \mathrm{cc}$. The same method was utilized in preparing the control mixtures for both the test subjects and controls. The injected monkeys were vigilantly monitored for 1 month and the symptoms were noted. This experiment concluded that multiple paralytic doses of poliomyelitis virus, in combination with very small amounts of vitamin C, were rendered non-infectious, as established by intracerebral injection of such mixtures into rhesus monkeys [10].

Several mosquito transmitted viruses have been successfully treated using high doses of IV vitamin C. For example, Gonzalez et al. [11] presented a case report on a 54-year-old Hispanic female who had Zika like symptoms. Some of the symptoms may include mild headaches, fever, joint pain, malaise, and conjunctivitis. These symptoms are also similar to dengue and chikungunya. While oral doses of vitamin $\mathrm{C}$ do not have the same ability to reach high blood levels, IV vitamin $\mathrm{C}$ is shown to produce clear clinical and pharmacological benefits, from 30 to 70 times higher than orally, which appears necessary in treating viruses. Due to the antiviral and antioxidant properties of vitamin C, after their patient was tested for Glucose-6-Phosphate Dehydrogenase (G6PD), IV vitamin $\mathrm{C}$ was administered by increasing the doses from $25 \mathrm{~g}$ and upping the dose by $25 \mathrm{~g}$ a day for three consecutive days, reaching $75 \mathrm{~g}$ on the third day.

Within 24 hours the symptoms had substantially improved and by the third day were gone. From this case it was established that IV vitamin $\mathrm{C}$ should be investigated further, as a possible treatment for acute viral infections [11]. Marcial-Vega et al. [12] used IV vitamin C from 25-50 grams with a 3cc of a 3\% hydrogen peroxide solution on 56 patients with the chikungunya viral infection. Using a Verbal Numerical Rating Scale-11, immediately before and after treatment. The mean Pain Score before treatment was at 8 and dropped to 2 after treatment for $60 \%$ of the patients, with 5 patients reporting 0 pain after the treatment, with no observed adverse reactions in any patient [12].

Hemila [13] reported on a new coronavirus in 2003, as the causative factor of severe acute respiratory syndrome (SARS). At that time there was no known treatment for SARS. Based on the available research it was known that vitamin $C$ was beneficial to the immune system, by reducing viral respiratory infections, and may support pneumonia patients. Noting that under certain circumstances that it may assist in reducing lower respiratory tract infections, and deserved further investigation [13]. According to Fowler et al. [14], their case presented the first report of virusinduced acute respiratory distress syndrome (ARDS) caused by an enterovirus/rhinovirus respiratory infection that used high dose IV vitamin $\mathrm{C}$ as a treatment.

From their clinical experience using IV vitamin $\mathrm{C}$ to treat acute sepsis, they used the same intervention for a 20 -year-old, previously healthy female who had gotten enterovirus/rhinovirus that quickly became ARDS. They reported in treating sepsis that high doses of IV vitamin C not only reduced multiple organ 
injury, but also inflammatory biomarker levels. After a 12-day hospital stay and a follow-up visit one month later, the patient was completely recovered without lung damage, suggesting larger trials utilizing IV vitamin $\mathrm{C}$ should be conducted to treat ARDS [14].

COVID-19, was first reported in Wuhan, China. ARDS is a main component of COVID that can be deadly due to cellular injury and organ failure. Studies have shown that high-dose oral vitamin $\mathrm{C}$ guards against viral infections. IV vitamin $\mathrm{C}$, as well as high oral doses of vitamin $\mathrm{C}$ have presented without serious side effects. Fifty moderate to severe COVID -19 patients received high-dose IV vitamin C in China. Doses fluctuated from $10 \mathrm{~g}$ and $20 \mathrm{~g}$ per day, administered over an 8-10 hour-period, with high-doses of vitamin $\mathrm{C}$ being given to critical patients. All of the patient's oxygenation index improved and all were eventually cured and released. An expert panel from $\mathrm{NIH}$, stated that high-dose of vitamin $\mathrm{C}$ is a safe and effective treatment, without serious side effects. Due to its known safety record, and since it is readily available, vitamin C, as well as other antioxidants may mitigate COVID-19 associated ARDS [15].

Boretti et al. [16] reported on the efficacy of IV vitamin C to treat the COVID-19 virus, because of the current controversy of using antiviral treatments that were developed for other diseases, to treat this new virus. Shanghai, as well as other medical doctors in China are now treating COVID patients with IV vitamin C, and are having positive results. COVID viruses increase oxidative stress and tax the immune system, which can lead to ARDS and death. They reported that over 300 clinical and scientific studies found vitamin $\mathrm{C}$ to be beneficial to treat sepsis and septic shock.

Other studies have shown positive outcomes using vitamin $\mathrm{C}$ to treat viruses, such as poliovirus, Venezuelan equine encephalitis, human lymph tropic virus type 1 (HTLV-1), human immunodeficiency virus (HIV) and rabies virus, in addition to demonstrating activity against influenza and herpes virus. Due to acute lung infections that may develop with COVID-19, clinical studies are showing that a timely intervention with mega dose vitamin C improves the outcome of COVID-19. They recommend continued studies on this therapy [16].

The diagnosis of any disease, especially cancer, is overwhelming to not only the person who receives this distressing information, but also to their family and friends. With exorbitant health care costs, both old and new research is proving that vitamin $\mathrm{C}$, does in fact have a place as an important, inexpensive therapy that can potentially be a lifesaving treatment. When the work of Cameron and Pauling was dismissed, what was barely mentioned in the scientific literature was that the form of vitamin $\mathrm{C}$ administered by them, was IV vitamin $C$ in conjunction with oral vitamin $C$, when the Mayo Clinic trial supposedly replicated the same study, they only used oral doses, that were administered for only 2.5 months, while Pauling and Cameron's trials treated the patients for the entire study period or up to 12 years [17].
Padayatty et al. [18] analyzed both the Mayo Clinic study and Pauling's study, and found that the Mayo Clinic's oral doses would have produced peak plasma concentrations of less than 200 $\mu \mathrm{M}$, while Pauling's intravenous dose would have peak plasma concentrations of nearly $6 \mathrm{mM}$, more than 25 times higher [18]. While vitamin $\mathrm{C}$ is generally considered safe, there are certain ethnicities, such as those from African, Asian, and Mediterranean descent who may have G6PD deficiency that can be harmed with high doses of vitamin C. This hereditary X-linked disorder affects at least 329 million people globally. Even though most G6PD patients may be asymptomatic during their lifetime, it is important when treating the above-mentioned ethnicities that screening is done as to avoid any potential contraindication to the patient [19].

The research on the safety and efficacy on various forms of vitamin $C$ over the last 80 plus years, is widely established. Currently, there are clinical trials and case studies taking place on vitamin C mega dose's, as a single therapy or in conjunction with other therapies around the globe. Essentially, all of these studies are proving that mega dose vitamin $\mathrm{C}$ is highly beneficial by enhancing the quality of life for the patient and mitigating the toxic effects of chemotherapy, shortening cold symptoms, and treating viruses with promising results. What the research is showing, even with COVID-19, is that vitamin C is a safe and effective treatment and is readily available to treat patients from COVID to cancer.

\section{References}

1. Aversa R, Petrescu RVV, Apicella A, Florian Ion T (2016) We are Addicted to Vitamins $C$ and E-A Review. American Journal of Engineering and Applied Sciences 9(4): 1003-1018.

2. Mayberry JA (2004) Scurvy and Vitamin C Food and Drug Law.

3. Albert Szent Gyorgyi (2018) Science History Institute.

4. Linus Pauling, American Scientist. Encyclopaedia Britannica.

5. Cameron E, Pauling L (1976) Supplemental ascorbate in the supportive treatment of cancer: Prolongation of survival times in terminal human cancer (vitamin C). Proc Natl Acd Sci 10: 3685-3689.

6. Blaszczak W, Barczak W, Masternak J, Przemysław Kopczyński, Anatoly Zhitkovich, et al. (2019) Vitamin C as a Modulator of the Response to Cancer Therapy. Molecules 24(3): 435.

7. Harris HR, Orsini N, Wolk A (2014) Vitamin C and survival among women with breast cancer: A Meta-analysis. European Journal of Cancer 50: 1223-1231.

8. Lv H, Wang C, Fang T, Ting Li, Guishuai Lv, et al. (2018) Vitamin C preferentially kills cancer stem cells in hepatocellular carcinoma via SVCT-2. Npj Precision Oncology 2: 1.

9. Satheesh NJ, Samuel SM, Busselberg D (2019) Combination Therapy with Vitamin C Could Eradicate Cancer Stem Cells. Biomlecules 10: 79.

10. Jungeblut CW (1935) Inactivation of Poliomyelitis Virus in Vitro by Crystalline Vitamin C (Ascorbic Acid). J Exp Med 62(4): 517-521.

11. Gonzalez MJ, Berdie MJ, Miranda Massari JR, et al. (2016) High Dose Intravenous Vitamin C Treatment for Zika Fever. JOM 31: 1.

12. Marcial Vega V, Idxian Gonzalez Terron G, Levy TE (2015) Intravenous ascorbic acid and hydrogen peroxide in the management of patients with chikungunya. Bol Asoc Med P R 107(1): 20-24. 
13. Hemila H (2003) Vitamin C and SARS coronavirus. J Antimicrob Chemother 52(6): 1049-1050.

14. Fowler III AA, Kim C, Lepler L, Malhotra R, Debesa O, et al. (2017) Intravenous vitamin $\mathrm{C}$ as adjunctive therapy for enterovirus/ rhinovirus induced acute respiratory distress syndrome. World J Crit Care Med 6(1): 85-90.

15. Cheng RZ (2020) Can early and high intravenous dose of vitamin C prevent and treat coronavirus disease 2019 (COVID-19)? Medicine in Drug Discovery 5: 100028.

16. Boretti A, Banik BK (2020) Intravenous vitamin C for reduction of cytokines storm in acute respiratory distress syndrome. PharmaNutrition 12: 100190.
17. Cantley L, Yun J (2020) Intravenous High-Dose Vitamin C in Cancer Therapy.

18. Padayatty SJ, Riordan HD, Hewitt SM, Katz A, Hoffer LJ, et al. (2006) Intravenously administered vitamin $\mathrm{C}$ as cancer therapy: three cases. CMAJ 174(7): 937-942.

19. Quinn J, Gerber B, Fouche R, Kenyon K, Blom Z, et al. (2017) Effect of High-Dose Vitamin C Infusion in a Glucose-6-Phosphate Dehydrogenase-Deficient Patient. Case Rep Med 2017: 5202606.

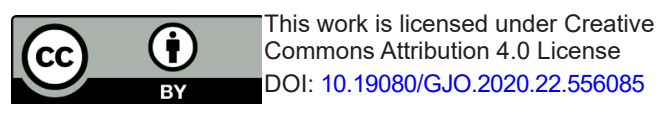

\section{Your next submission with Juniper Publishers will reach you the below assets}

- Quality Editorial service

- Swift Peer Review

- Reprints availability

- E-prints Service

- Manuscript Podcast for convenient understanding

- Global attainment for your research

- Manuscript accessibility in different formats ( Pdf, E-pub, Full Text, Audio)

- Unceasing customer service

Track the below URL for one-step submission https://juniperpublishers.com/online-submission.php 